\title{
Freirean principles and critical literacy to counter retrograde impulses in the Curriculum and Assessment Policy Statement
}

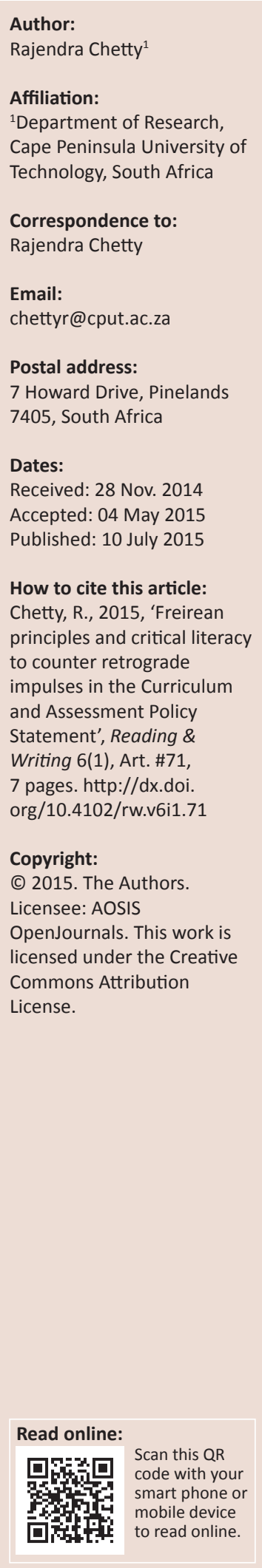

Inherent in the Curriculum and Assessment Policy Statement (CAPS) document are inferences of transmission and reproduction that run counter to the emancipatory imperatives of core educational policy documents enacted after democracy in 1994. Some structural inadequacies in implementation of the first curricular changes to outcomes-based education have opened the way to reactionary and retrograde pedagogy which appears to privilege the teacher and textbook as sole authorities in the classroom. The purpose of this article, therefore, is to warn against teacher-centred pedagogy and restate the significance of Freirean principles in the establishment of a student-centred educational environment, specifically in the field of critical literacy. In defence of Freirean thought, a re-consideration of literacy and critical literacy grant legitimacy to the learner and demonstrate that individual experience is foundational to knowledge construction in a participatory manner which accords with the vision and original principles of education in the new South Africa.

\section{Introduction}

[T] he curricula of schools are other people's knowledge, imposed on students. Not surprisingly, some students do not bother to make personal sense of this knowledge but merely play the school 'game' of rote learning and reproducing the curriculum knowledge. (Habermas 1984:220)

The People's Education Movement of the 1980s provided a recognisably alternative and radically transformative departure point for literacy development in South Africa. Fundamentally, People's Education addressed the loss of agency in its emancipatory rhetoric and espousal of Freire's principles of pedagogy of the oppressed (Nekhwevha 2002). During the liberation struggle, literacy reformists embraced the ideals of Freirean critical pedagogy that seemed to speak directly to the need for transformation of education in South Africa. Traces of Freirean rhetoric became embedded in the rationales for the three curriculum reconstruction initiatives after 1994. It is ironical and worrying, therefore, to note the liberation rhetoric in the 2011 Curriculum Assessment Policy Statement (CAPS), which espouses the principles of social transformation but fails to enact them. It promises to ensure that the educational imbalances of the past are redressed, that equal educational opportunities are provided for all sections of the population: it encourages an active and critical approach to learning rather than the rote and uncritical learning of given truths (Department of Basic Education 2011:4). But, despite the espousal of liberal prerogatives, there are some indications that retrograde impulses are drawing national education back towards a pre1994 programme of memorisation: 'learning' the contents of a single textbook for each subject. The Council for Quality Assurance in General and Further Education and Training notes that:

The move from OBE [outcomes-based education] has also resulted in a shift from a cooperative, discoverybased learning, where the learner is a participant in the learning process, as a negotiator of meaning, to content-driven learning, where the learner is a recipient of a body of pre-determined knowledge. (Umalusi 2014:25)

The purpose of this article, therefore, is to warn against teacher-centred pedagogy and restate the significance of Freirean principles in the establishment of a student-centred educational environment, specifically in the field of critical literacy. Any retrogressive steps at this time would deny the demonstrable value of recognising the learner as the centre of knowledge construction and return us to the teacher as central dispenser of facts to be learnt by heart without reflection, questioning or growth of the individual. The opposition to more democratic modes of pedagogy is marked and active not only in South Africa but also in the USA:

The Los Angeles Times reported that a conservative UCLA alumni association offered students up to $\$ 100$ per class for taping lectures of certain UCLA professors identified with left-wing or liberal causes, naming them 'The Dirty 30'. (Katz \& Ryan 2010) 
In spite of these daunting attacks in a time of change, there are still professors willing to persevere and 'speak against injustice, exclusion and silencing wherever they occur' (Katz \& Ryan 2010:128)

Since 1997, there has been a steady shift away from Freirean principles in implementation of OBE across the country. This movement is more marked with each revision of the post1994 school curriculum. The iterations of the curriculum were OBE (C2005), National Curriculum Statement, the Revised National Curriculum Statement and recently, CAPS. Constructivist practice explicitly espoused in the first round of curriculum reform in C2005 affirms the agency of learners as constructors, rather than passive receivers or acquirers of knowledge. It must be conceded, however, that some difficulties in implementing constructivism have been experienced in the USA and several other countries: 'Classroom teachers are finding the implementation of constructivist instruction far more difficult than the reform community acknowledges' (Windschitl 2002:131).

In South Africa, there were numerous obstacles inherited from the apartheid system which hindered effective implementation of OBE. The size of classes was a major difficulty to start with. OBE requires small classes so that attention can be paid to individual needs of students. In South Africa, classes are commonly made up of sixty students: almost double the limit for OBE pedagogy. OBE assumes the existence of such infrastructure as libraries at every school. In New Zealand or Scotland, where OBE is successfully implemented, such infrastructure does exist. Libraries assist as resource centres which allow learners to investigate and explore topics raised in class. Without this support structure, OBE can hardly be used. Another critical factor was the assumption that parents would be able to impart skills and knowledge from home. Again, as a result of the inequities of apartheid, parents were unable to assist their children to the desired extent. Parents themselves had been the victims of a system of segregated schooling in which far less money was spent on black, mixedrace or Indian students than was allowed for white pupils. As a result of class size, lack of libraries and parental support, OBE failed to raise the level of literacy and knowledge acquisition generally, as originally envisaged. Pass rates fell dramatically as the dream of a learner-centred system collapsed under the strain of repairing the damage from the past and adjusting to the future. Teachers attempted to instil the ideals of OBE but cuts in teachers' training colleges meant that there was a lack of facilities from which to train the teachers themselves and create a form of consistent constructivist pedagogy adapted to the peculiar challenges of post-1994 South Africa.

Spady (2008), the chief architect of OBE, had a vision of equitable and effective schooling for all in the new South Africa. But he too was caught in the morass of inherited structural difficulties of a broken system. His comments recently evidence a profound disillusionment:

It is regrettable that the message I carried to South African educators in 1997 about OBE as I had come to know it had little, if any, influence on South African educational reform policy. Had there been stronger conceptual understanding and agreement regarding the issues described above, I believe the country's educational leaders would have been able to make a more constructive choice about the reforms they sought to implement during the first Mandela government. Equally regrettable was my inability to engage the country's academic community in a serious consideration of OBE beyond Curriculum 2005 itself. The outspoken Curriculum 2005 critics of the day - like Jonathan Jansen and Linda Chisholm - were attributing many of the weaknesses, dangers, and failures that they saw in Curriculum 2005 and the National Department of Education's policies, curriculum focus, and implementation strategies to OBE in the larger sense. And I had no platform, beyond the original lecture tour, for addressing these misunderstandings. (Spady 2008:10)

So now, with a decade of confusion about OBE behind us, I would encourage my South African colleagues to stop referring to OBE in any form. It never existed in 1997, and has only faded farther from the scene since. The real issue facing the country is to mobilize behind educational practice that is sound and makes a significant difference in the lives of ALL South African learners. Empty labels and flowery rhetoric are no longer needed; but principled thinking and constructive action are. (Spady 2008:11)

It is fortuitous that Spady ends with the term 'constructive'. Although OBE may have encountered difficulties in the South African context, a knee-jerk return to the apparently safe ground of pre-1994 textbook-based education will do little to solve the fundamental and inherently political issues of good education for all. Visible pedagogy is assumed to be free of a political agenda: educators are presumed to convey knowledge in a secure way that equips learners to gain foundational knowledge which will ultimately allow them to gain skills needed to join the job market. This seemingly innocent model is in fact identifiably capitalist in nature - contrary to the egalitarian vision of a Mandelan landscape which makes up for the inequalities of the past. Re-installation of textbook education is a re-appropriation of the very capitalist, exclusionary thinking that caused so many of the colonial and apartheid wrongs of the country.

Freirean inclusiveness is more politically appropriate in the reconstitution of democratic thought and practice in South Africa than a relapse to teacher-centred authority models. In constructivist practice, differentiated teaching is inevitable; sequencing and pacing depend on what the learner brings to the process. Constructivist practice falls within the ambit of 'invisible pedagogy' (Bernstein 1990). The antithesis of invisible, that is, visible pedagogy, is characterised by transmission modalities, explicit sequencing and pacing rules. Bernstein points out that visible pedagogy produces stratification of learners. If learners fall behind, a repair system has to be in place or the rules have to be relaxed. Visible pedagogy privileges teacher dominance, which in turn suggests prescriptive pedagogical models of the pre1994 era. This reactionary trend against Freirean pedagogical initiatives is observed in many countries:

In search of sustainable systemic success, school reform programs are evolving into a distinctly different form of school reform that has been described as the 'Third Age' of school reform. (Rafferty 2010:15) 
Although constructivist thought was prominent in the liberal intimations of the new education system that emerged after 1994 and although it was subsequently embedded in the new system's foundational articulation, emancipatory and participatory emphases have been steadily eroded after each revision of the original document for democratic education in the new South Africa. Within the discipline of English, but not exclusive to it, the crucial task of establishing literacy for all is linked to the development of critical literacy, which is in turn predicated upon a constructivist learning environment of open debate and a culture of questioning.

\section{Literacy and constructivism}

Literacy may be enhanced by various reading improvement strategies at a technical level yet often in the short-term only, if 'literacy' is defined as control of language. But, the term 'literacy' denotes a more significant developmental aspect of education through the open recognition of participant learner experience in the classroom, the sharing of such experience and construction of a democratic type of knowledge which is built on the foundation of mutual respect for a variety of histories, gender identities and religious or political convictions. In discovering the self and articulating identity socially, in stimulating the growth of responsible adults, diverse cultural experiences and knowledge are revealed and shared in a classroom. No culture is, or can be, neutral. Education is the unmasking of apparent neutrality just as literacy in its profound sense is the ability to read society, relations within it and texts or structures of signification which reflect the individual and relations between individual and society in all the multiplicity of meanings which those complex inter-relations produce.

Critical literacy mandates the individual reader as independent critical thinker, in contrast to transmission pedagogy, which privileges the teacher as expert, sole controller or conveyor of the text's meaning. This unilateral process is perilously close to inferences extant in the new CAPS document. Marxist, feminist and queer theory oppose such replication of conformist capitalist ideology and propose the classroom not as a site for memorisation of a teacher's utterances, but as a secure arena for exposing and debating the underlying tensions, conflict and discord that mark individual experience (Zozakiewicz \& Rodriguez 2007:404). Elsasser and John-Steiner (1987:45) maintain that only programmes that build upon cognitive processes can help individuals meet the long-term objective of using their literacy as a tool of personal growth and social transformation. Short-term improvement in literacy skills can be achieved by motivating students and by reinforcing their written work but the experiences of students should be given preeminence in an emancipatory curriculum, therefore critical educators must learn how to understand, affirm and analyse such meaning (Freire 1985:xxi; Giroux \& McLaren 1991:167). Freire emphasises that all knowing begins with experience: in his terminology, 'knowledge is made from experience' (Freire \& Macedo 1987:87). Critical educational studies include the development of forms of knowledge and social practices that validate the experiences students bring to their respective institutions. Such experiences should form the basis of the teaching programme to ensure that students have an active voice in the content taught instead of the traditional approach of silencing them by ignoring cultural capital. Critical teaching creates a process of learning and knowing that invariably involves theorising about the experiences shared in the dialogue process (Freire \& Macedo 1995:381).

Freire views the students' experiences as central to the construction of authentic knowledge: 'they bring with them opinions about the world, and about life' (Freire \& Horton 1991:57). Education starts with the experiences of students and either reinforces or challenges existing social forces that attempt to keep them passive. Students' experiences or 'hidden voices' (Wallerstein 1987:35) need to be revealed; otherwise they can block learning. Such blocks can be emotional (e.g. low self-esteem), structural (e.g. lack of contact with English speakers) or socio-economic (e.g. prejudice). The emotional power behind these experiences can inspire learning. By helping students articulate their concerns in the classroom, teachers help them understand the blocks and move forward.

An appropriate curriculum should be based on, and derived from, the cultural capital of the students to be educated. During the pre-1994 era, the culture of the oppressor was imposed on the oppressed (both students and teachers), it invalidated their own culture and led to self-depreciation resulting from their internalisation of the opinion the oppressors held of them (Freire 1971:122). Reid (1982:14) found that the uncritical acceptance of many black teachers of the educational system in the eighties corroborated Freire's diagnosis that they were unwilling to consider reform of the system, were least interested in changing the curriculum or the examination system and strongly favoured some of the more traditional and inappropriate aspects of the old curriculum. The structure of their thought, therefore, had been conditioned by the contradictions of the concrete, existential situation by which they were shaped (Freire 1971:22).

Critical interpretation during reading presupposes involvement and experience. Rosenblatt (1985), within the Freirean discourse, insists on student involvement in the literary event and the treatment of the text more as an experience than a lesson or object to be studied. She identifies two stances that readers can take during literary study - an efferent stance that focuses a reader's attention on information to be retained after reading and an aesthetic stance that occurs when the reader's attention is on the livedthrough experience of the text and thoughts, feelings, images and associations which are evoked as the text is read. The latter fosters the development of a reader's understanding of a work's personal significance. An efferent approach, on the other hand, assumes that students' personal opinions are not valued and that there exists a correct answer which they are expected to reach. An aesthetic stance ensures that students truly live the literary experience and are not encouraged to distance themselves from the text.

The efferent approach has been exacerbated by the undue stress placed on New Criticism and Formalism, theories 
which encouraged an authoritarian academic environment and canonical cultural expressions. An Anglo-American dominance emerged in the 1950s which created a degree of paternalism over educational structures in developing societies. The paternalism evident in these authoritarian concepts rendered students spectators in the academic conversation rather than intellectual participants. The dominance of developed societies reinforced the top-down authority of apartheid education and effectively silenced the majority of learners and thinkers. The task of the teacher was that of 'filling' students with 'hollow, alienated verbosity' (Hill 1990:38). The student mechanically recorded, memorised and repeated the imposed content.

Freire counters this situation by insisting that there be a determined effort by the lecturer or teacher to relinquish the role of expert and provide the critical, reconstructive space for learners to sort out their contradictions or conflicts, confirm themselves and gain understanding about the richness of other cultures or voices. The teacher's direction of education should include helping learners to become involved in planning education, stimulating them to create the critical capacity to considerand participatein the direction and dream of education, rather than following blindly (Freire \& Macedo 1995:379). This paradigm increases the awareness of the contradictions hidden or distorted by everyday understandings: it creates a critical community in the classroom, empowering learners to rethink their world and reinterpret their experiences. Factors such as social convention, class, historical positioning, gender and individual experience result in a multiplicity of readings and meaning construction. There cannot be one 'real' meaning because a variety of interpretations place emphasis differently during each stage of the reading process.

Any student's response to literary texts is naturally conditioned to a certain extent, by the student's own reading experience, cultural background and biases, the more impersonal factors of culture and society, and certain levels of literary competence. The teacher's attempt at constructing the meaning of a text is naturally influenced by subjective bias as well. It is therefore logical that all interpretations of meaning and all meaning construction in literature, because of the subjective nature of the exercise, result in an indefiniteness or infinity of meanings as subjective bias and cultural conditioning deny a single objective or finite truth.

The notion of experience and meaning are historically integral to South African writers and readers as the construction of new meaning based on the experiences of the oppressed was more a social and political task than an aesthetic one in the pre-1994 years of struggle. Coupled with this social manifesto was a growing determination not to be hampered by the literary conventions or critical and aesthetic demands of the white establishment under apartheid. Many African poets realised how irrelevant developed society's literary language was to their experiences. They reflected instead the experiences of the township, adopting an admixture of African grammar, local idiom and jazz rhythm. Their works were forged from a collocation of words from Afrikaans,
English and African languages. These 'generative words' are keys to areas of marginalised knowledge or life that the poet wants to open up (Finlay \& Faith 1987:30): they reflect a phonetic richness and contain social, political, economic or cultural implications. This enabled the township reader to identify with the poetry. As a Black Consciousness strategy, it overtly alienated the conservative academe and by that very alienation was often able to shock readers into a new awareness of the poet's message.

Perhaps this is why such works are still marginalised from the curriculum. This writing conflicts with the individualistic production model and the capitalist distribution model of developed society's tradition. What is oral, directed at or part of an African community is the 'other' and does not fit onto the literary 'high culture' tradition. The reconstruction process must of course be guarded against: simply replacing 'high culture' content with local content. More appropriately, the process of reconstruction should include the need to engage critically the experiences that learners bring to the classroom. This means that such experiences, in their varied cultural forms, have to be interrogated to uncover their strengths and weaknesses (Aronowitz \& Giroux 1986:156). Students should be provided with the skills and knowledge they need in order to transform the world according to their own vision. A major precondition for such an exercise is that students learn how to appropriate the codes and vocabularies of different cultural experiences. Diversity was reflected as a foundational criterion in the OBE curriculum documents, yet it has been tellingly neglected in the later revisions.

Provision for critical educational studies in curriculum reconstruction enables learners to see that their understanding of all cultures' texts (from philosophical treatises to popular television shows) is a result of situatedness in a complex network of gender, class and race relations that provide each subject with a unique set of certain concepts (Zavarzadeh \& Morton 1994:19). Students should take into account that reading and meaning change depending on different factors such as background, race, subjectivity, access to knowledge or economic limits.

No culture is neutral (Apple 1990:1): both Freire and Foucault remind educators of their task to unmask the assumed neutrality of cultural institutions. The interaction of teacher and student does not take place in a vacuum: education starts from the experiences of people. It either reinforces or challenges existing social forces that keep them passive (Wallerstein 1987:33). Door (2014) agrees:

Education practice in action cannot be divorced from the essential nature of the practitioner, who is a psycho-physical unity. Change of practice, in the service of humanisation, is possible, but involves not only an intelligent critique of self and world, but awareness of how action is manifesting. (p. 88)

Similarly, literature is political and serves somebody's interest as it is 'someone's selection, someone's vision of legitimate knowledge, one that in the process of enfranchising one group's cultural capital disenfranchises another's' (Apple 
\& Christian-Smith 1991:4). The separation of art from the base of society was evident at the universities which did not acknowledge African writings. This was a deliberate attempt to neglect such artistic expression because of its social and political commitment; not so much because of the constraints of traditional forms and literary conventions.

\section{Critical literacy}

As a form of social redress, meaning construction, an essential principle of Freirean pedagogy, enhances the quality of student readership and critical literacy, whilst critical dialogue and cognition help re-conceptualise the functions of literary studies and didactics. Most importantly, it is in keeping with the aim of the curriculum reconstruction programme for the enhancement of critical literacy: as a means of liberating the creative and critical potential of students. CAPS appears to discount this creative engagement of the learner as individual interpreter in a worrying emphasis on teacher-centred tuition.

Ennis (1987:10) defines critical thinking, the heart of critical literacy, as a practical reflective activity that has reasonable belief or action as its goal. Critical thinking skills that help transform the classroom into a community of inquiry include reasoning skills, inquiry skills, concept-analysis skills and translation skills (Lipman 1987:154). Cognitive process instruction is more than a shift of emphasis from basic skills; it implies a radical change in our current conception of learning. Students can learn only when they are actively involved in piecing together their own ideas, when they have a will to doubt and when their interpretation is respected.

The origins of the constructivist approach to cognition are ancient; Galileo said: 'you cannot teach a man anything; you can only help him to find it within himself' (eds Lockhead \& Clement 1979:2). Young (1992:23) maintains that if new knowledge is learnt in a shallow way, it is difficult for the knowledge to be made into the students' own or form part of their reality. Habermas (1984:220) also contends that genuine conceptual learning occurs only when learners make their own sense of knowledge:

$[T]$ the curricula of schools are other people's knowledge, imposed on students. Not surprisingly, some students do not bother to make personal sense of this knowledge but merely play the school 'game' of rote learning and reproducing the curriculum knowledge.

A cognitive approach emphasises the role of the student as active participant and not, as Habermas warned, a passive recipient.

Giroux (1991:171), in outlining the cognitive approach, distinguishes between knowledge about learning (univocality, precision, logic) experienced in school as opposed to knowledge of, or the analogic dimension (equivocation, ambiguity, description) experienced by students in the street. If knowledge is a given, it is of a linear or relatively unproblematic nature and does not engage student experience within critical educational studies: it is characteristic of transmission education. The teaching of literature using the traditional didactical approach of transmission education was described by Freire as banking education: authoritarian teachers 'deposit' knowledge in the students' minds. This is a process that 'anaesthetizes and inhibits creative power' (Freire 1971:58). Banking education assumes that students' viewpoints and voices are of secondary importance to the authoritative knowledge passed on by the teacher (Freire 1971:58).

The paternalism of this approach is essential to the maintenance of an oppressive political and social order (and of the neo-liberalism of the current dispensation): it ensures that students who complete the courses remain passive and unquestioning, stripped of critical literacy. According to Hill (1990:70), banking education may be beneficial for the students in particular situations, for example, when motivated learners wish to obtain specific bodies of knowledge within a paradigm with which they are already familiar and knowledgeable. A negative result of banking education is what Freire refers to as marginalisation: by promoting myths about reality and maintaining the dominant ideology of the institution, educators oblige learners to be marginalised, on the fringe of, or outside reality. In the USA there have been several productive and informative projects into Freirean pedagogy which are pertinent to conditions in South Africa. One such study is Maxima, a longitudinal study 'into how teachers translate their multicultural, gender inclusive and socio-constructivist understanding into their own policies' (Zozakiewicz \& Rodriguez 2007:404). Such research marks the direction in which liberal education in the new South Africa could be advancing.

Both schools and universities were guilty of the conspiracy with apartheid prior to 1994 by engaging in the process of marginalisation, exclusion and transmission education. The timely use of a critical educational studies approach might have awakened serious discussion of political principles hidden in the curricula of those educational institutions which endeavoured to stifle vibrant interaction between free thinking and political life. Academics and teachers feared that the dominant institutional discourse, the curriculum and their positions might be at risk if the status quo was not maintained. The National Commission for Higher Education (1996:2) reiterated that historically black universities were considered teaching universities and not research universities like their white counterparts. Thinking was considered irrelevant to their curriculum as their primary role was to impart knowledge to the unenlightened who came from disadvantaged schools and communities. Such a stratified and authoritarian structure - privilege for a minority and deprivation for the majority - could be the result, again, if the country returned to visible pedagogy, which is inferred in much of the CAPS documentation.

Some failure in the implementation of OBE and constructivist initiatives has led to an over-reaction against Freirean thinking in the formulation of CAPS. The chief relay of visible pedagogy that has overtaken curriculum development in its 
2011 iteration, i.e. CAPS, is textbook production. For example, CAPS language statements include work schedules for each grade elaborated in fine detail and within strict parameters. Publishers, who need to have their books prescribed, respect such minute prerogatives. Assessment tasks are designed that are in essence external examinations, divorced from genuine formative assessment practices for learners as early as in Grade 4. The 'critical' element in the rationales for CAPS is vitiated in the process of writing by the work schedules for the review panellists. Stratification, which was a feature of apartheid education, may thus be re-introduced by means of this unforeseen dominance of publishers' mercantilist prerogatives. Such layering of achievement groups runs counter to the democratic initiatives of critical literacy in the classroom.

Textbooks are produced for learners with perceived deficits in performance and are class referenced. For example, there are first-additional language (FAL) textbooks for 'rural' or 'township' learners in which the text reflects the 'lexical pedagogic code' that Bernstein (1990) describes and other FAL books for those judged likely to manage a more 'syntactic' code. When the books are distributed to broad categories of learners, the reproductive effects of these practices are selfexplanatory. Learners are provided with material pegged according to their perceived socio-economic status, not marked 'beginner, elementary or advanced', which would give them some purchase in evaluating their own progress. By pre-determining the likely competence of learners in this way, identities are inscribed on them. During the apartheid era, the political elite engineered identities to suit the desired distribution of power. At present, commercial interests perpetuate the trajectories of marginalisation by shrinking from the risk that authentic change demands.

Griffith, a critic of Freire's theories, argues that his impassioned preaching on critical pedagogy, cognition and the notions about the necessity for making the student an active, questioning, thinking participant in the formal education process are neither new nor revolutionary (Griffith 1972:67). For Griffith, Freire simply repeats the philosophy of education proposed by Dewey (1940). Freire acknowledges his indebtedness to Dewey (Collins 1977:84), but develops Dewey's ideas on human experience and proposes that knowledge, as with experience, is historically founded yet continuously changing. This concept regards knowledge as dynamic: it is influenced by power relations and is important in the curriculum reconstruction process.

To facilitate such a process, Beyer and Apple (1988:5) provide a valuable framework that requires us to think about education critically and cognitively by asking a range of questions:

1. Epistemological. What should count as knowledge? Should we take a behavioural position, one that divides knowledge and knowing into cognitive, affective, and psycho-motor areas, or do we need a less reductive and more integrated picture of knowledge and the mind, one that stresses knowledge as process?
2. Political. Who shall control the selection and distribution of knowledge and through what institutions?

3. Economic. How is the control of knowledge linked to the existing unequal distribution of power, goods and services in society?

4. Ideology. What knowledge is of most worth? Whose knowledge is it?

5. Technical. How shall curricular knowledge be made accessible to students?

6. Aesthetic. How do we link curriculum knowledge to the biography and personal meaning of the student?

7. Ethical. How shall we treat others responsibly and justly in education? What ideas of moral conduct and community serve as the underpinnings of the ways learners and teachers are treated?

8. Historical. What traditions in the field already exist to help us answer these questions? What other resources do we need to go further?

By taking these questions into consideration in the process of curriculum reconstruction, we create an educative environment in which cognitive development is central: we begin to understand the reconstruction process as an inherently political and moral one (Apple 1979:111). Freire's keen understanding that hope 'is the very matrix for any dialectic between hope itself, anger or indignation, and love' (Freire 2004:xxvii) makes his political project timelier today in view of the dehumanising policies the world is now facing through neo-liberalism and 'hot-button cowboy militarism' (Macedo 2013:90).

Unfortunately, within the South African context, there was a tacit inculcation of the belief in the value of literary craftsmanship and liberal culture of the arts resulting in educators, as custodians of knowledge, interpreting texts on behalf of readers. Teachers using a cognitive approach will encourage conscientisationin theclassroom. Behardien(1989:ii) views it as a process of re-interpreting dominant perceptions and denouncing those which do not adequately explain society. Conscientisation has to do with the development of a new mode of expression: a critical discourse. Students are guided through dialogue to explore and interpret in their own way. The process, similar to Dewey's (1940) problemsolving approach, involves critical questioning, forming opinions, testing hypotheses and making decisions. Students are encouraged to see reality clearly and critically, resulting in a positive teaching and learning environment, a sincere appreciation of the value of learning and a development of cognitive skills to solve practical problems.

\section{Conclusion}

Given the current threat of a relapse into rote learning, it was necessary and salutary in the first part of this article to recall the significance of literacy as it represents the myriad of reasons for initially basing the new educational structure upon Freirean principles. The second part of the article highlights the role of critical literacy in the recognition of difference and otherness. Literacy in its profound sense and 
critical literacy as exemplar of agentic maturity are essential field-markers in the recuperation of South Africa's intellectual and social landscape. South African education needs to take note of such boundaries, re-commit itself and re-embrace a cognitive approach as it is conducive to the development of autonomous, rational young South African citizens. The Curriculum 2005 document, which heralded a new era in education, although contentious in some academic circles that felt OBE is doomed to fail (Jansen 1998:321), correctly shifted priorities in education from learning to thinking and required a redefinition of the function of the classroom. Alternative curriculum strategies are necessary to counter the pedagogy of oppression and ensure the intervention of critical educational studies. Now there is a danger that education is slipping back to models of visible pedagogy that replicate, in significant ways, pre-1994 practice.

Critical literacy ensures that we succeed in presenting knowledge as a potentially emancipatory force in learners' lives. The relation between analysis in the classroom and critical thought in general has to be illuminated so that learners leave the institution with minds of their own and a critical awareness that generates social change. When we develop in learners some of the expertise necessary for decoding structures of signification, we equip them intellectually to read our own practices, our institutions and the world as a text. When this happens, any authoritarian, hierarchical or exclusionary qualities that we reflect in our choice of texts, courses and reading lists, our relations to learners or our teaching strategies, can be identified. Such a goal demands curriculum restructuring that encourages learners to see connections between the text and the[ir] world, increasing their perceptions concerning the link between power and truth and exposing them to excluded images of otherness.

\section{Acknowledgements}

\section{Competing interests}

The author declares that he has no financial or personal relationships which may have inappropriately influenced him in writing this article.

\section{References}

Apple, M.W., 1979, Ideology and curriculum, Routledge, London. http://dx.doi. org/10.4324/9780203241219

Apple, M.W., 1990, Ideology and curriculum, Routledge, New York. http://dx.doi. org/10.4324/9780203241219

Apple, M.W. \& Christian-Smith, L.K., 1991, 'The politics of the textbook', in M.W. Apple \& L.K. Christian-Smith (eds.), The politics of the textbook, p. 4, Routledge, New York.

Aronowitz, S. \& Giroux, H.A., 1986, Education under siege: The conservative, libera and radical debate over schooling, Routledge \& Kegan Paul, London. http://dx.doi. org/10.4324/9780203222034

Behardien, E., 1989, 'A critical study of Paulo Freire's concept of the culture of silence and the liberatory role of education from cultural domination', MA thesis, Faculty of Education, University of the Western Cape, Bellville.

Beyer, L.E. \& Apple, M.W., 1988, The curriculum process: Problems, politics and possibilities, State University of New York Press, Albany.

Bernstein, B., 1990, The structuring of pedagogical discourse: Class, codes and control, vol. IV, Routledge, London. http://dx.doi.org/10.4324/9780203011263

Collins, C.B., 1977, Paulo Freire: His life, works and thought, Paulist Press, New York.

Department of Basic Education, 2011, Curriculum and Assessment Policy Statement: Senior Phase, Grades 7-9, Government Printing Works, Pretoria.
Dewey, J., 1940, My pedagogic creed, Putman, New York.

Door, V., 2014, 'Critical pedagogy and reflexivity: The issue of ethical consistency', International Journal of Critical Pedagogy 5(2), 88-99.

Elsasser, N. \& John-Steiner, V., 1987, 'An interactionist approach to advancing literacy', in I. Shor (ed.), Freire for the classroom: A sourcebook for liberatory teaching, pp. 45-62, Boynton/Cook, Portsmouth.

Ennis, R.H., 1987, 'A taxonomy of critical thinking dispositions and abilities', in J.B. Baron \& R.J. Sternberg (eds.), Teaching thinking skills: Theory and practice, pp. 9-26, W.H. Freeman, New York.

Finlay, L.S. \& Faith, V., 1987, 'Illiteracy and alienation in American colleges: Is Paulo Freire's pedagogy relevant?', in I. Shor (ed.), Freire for the classroom: A sourcebook for liberatory teaching, pp. 63-86, Boynton/Cook, Portsmouth.

Freire, A.M.A., 2004, 'Prologue', in P. Freire (ed.), Pedagogy of indignation, p. xxvii, Paradigm, Boulder.

Freire, P., 1971, Pedagogy of the oppressed, transl. M.B. Ramos, Continuum, New York.

Freire, P., 1985, Politics of education: Culture, power and liberation, Bergen \& Garvey, South Hadley.

Freire, P. \& Horton, M., 1991, We make the road by walking: Conversations on education and social change, Temple University Press, Philadelphia.

Freire, P. \& Macedo, D.P., 1987, Literacy: Reading the word and the world, Bergin, South Hadley.

Freire, P. \& Macedo, D.P., 1995, 'A dialogue: Culture, language and race' Harvard Educational Review 65(3), 377-402. http://dx.doi.org/10.17763/ haer.65.3.12g1923330p1xhj8

Giroux, H.A., 1991, 'Modernism, postmodernism and feminism: Rethinking the boundaries of educational discourse', in H.A. Giroux (ed.), Postmodernism, feminism and cultural politics, pp. 1-18, State University of New York Press, Albany.

Giroux, H.A. \& McLaren, P., 1991, 'Radical Pedagogy as Cultural Politics: Beyond the Discourse of Critique and Anti-Utopianism', in M. Zavarzadeh \& D. Morton (eds.) Texts for change: Theory/pedagogics/politics, pp. 152-186, University of Illinois Press, Champaign.

Griffith, W.S., 1972, 'Paulo Freire: Utopian perspectives on literacy education for revolution', in S.M. Grabowski (ed.), Paulo Freire: A revolutionary dilemma for the adult educator, pp. 67-82, Syracuse University Publications, New York.

Habermas, J., 1984, The theory of communicative action, vol. 1, Heinemann, London.

Hill, P.G., 1990, 'Implications of Paulo Freire's thought for North American education', MA thesis, Department of Education, McGill University, Montreal.

Jansen, J.D., 1998, 'Curriculum reform in South Africa: A critical analysis of outcomes based education', Cambridge Journal of Education 28(3), 321-331. http://dx.doi. org/10.1080/0305764980280305

Katz, S. \& Ryan, D., 2010, 'Critical educators at work in Chicago: Connecting students to communities', International Journal of Critical Pedagogy 3(2), 127-150.

Lipman, M., 1987, 'Some thoughts on the foundations of reflective education', in J.B. Baron \& R.J. Sternberg (eds.), Teaching thinking skills: Theory and practice, pp. 151-161, W.H. Freeman, New York.

Lockhead, J. \& Clement, J. (eds.), 1979, Cognitive process instruction, Franklin Institute Press, Philadelphia.

Macedo, D., 2013, 'Situating pedagogy of the oppressed after Nita Freire', International Journal of Critical Pedagogy 5(1), 82-100.

National Commission for Higher Education, 1996, National Commission on Higher Education Report: A framework for transformation, NCHE, Pretoria.

Nekhwevha, F., 2002, 'The influence of Paulo Freire's "Pedagogy of Knowing" on the South African education struggle in the 1970s and 1980s', in P. Kallaway (ed.), The history of education under apartheid 1948-1984: The doors of learning and The history of education under apartheid 1948-1984: The doors of learn
culture shall be opened, pp. 134-144, Pearson South Africa, Cape Town.

Rafferty, J.M., 2010, 'Critical choices in school reform', International Journal of Critical Pedagogy 3(2), 15-35.

Reid, J., 1982, English literature in South African senior schools: A critique of set books, University of Cape Town, Cape Town.

Rosenblatt, L.M., 1985, 'The transactional theory of the literary work', in C.R. Cooper (ed.), Researching response to literature and the teaching of literature, pp. 33-53, Ablex, Norwood.

Spady, W.G., 2008, 'It's time to end the decade of confusion about OBE in South Africa', Suid-Afrikaanse Tydskrif vir Natuurwetenskap en Tegnologie 27(1), 17-29.

Umalusi, 2014, What is the CAPS package? Business, commerce and management, Umalusi, Pretoria.

Wallerstein, N., 1987, 'Problem-posing education: Freire's method for transformation', in I. Shor (ed.), Freire for the classroom: A sourcebook for liberatory teaching, pp. 33-44, Boynton/Cook, Portsmouth.

Windschitl, M., 2002, 'Framing constructivism in practice as the negotiation of dilemmas: An analysis of the conceptual, pedagogical, cultural and political challenges facing teachers', Review of Educational Research 72(2), 131-175. http://dx.doi.org/10.3102/00346543072002131

Young, R., 1992, Critical theory and classroom talk, Multilingual Matters, Bristol.

Zavarzadeh, M. \& Morton, D., 1994, Theory as resistance, politics and culture after (post) structuralism, Guildford Press, London.

Zozakiewicz, C. \& Rodriguez, A., 2007, 'Using socio-transformative constructivism to create multicultural and gender-inclusive classrooms: An intervention project for teacher professional development', Educational Policy 21, 397-414. http://dx.doi. org/10.1177/0895904806290126 